\title{
The Language of Food and Wine Tourism on the Web
}

\author{
Chiara Meluzzi ${ }^{{ }^{*}}$ \\ (iD) 0000-0002-2291-006X
}

\author{
Silvia Balsamo ${ }^{1}$ \\ (D) 0000-0001-7670-5769 \\ ${ }^{1}$ University of Pavia, ITALY \\ ${ }^{*}$ Corresponding author: chmeluzzi@gmail.com
}

Citation: Meluzzi, C., \& Balsamo, S. (2021). The Language of Food and Wine Tourism on the Web. Online Journal of Communication and Media Technologies, 11(2), e202104. https://doi.org/10.30935/ojcmt/10821

\begin{tabular}{ll} 
ARTICLE INFO & ABSTRACT \\
\cline { 1 - 2 } Received: 4 Sep 2020 & $\begin{array}{l}\text { The language of tourism is considered as one of the many specialized languages, which is } \\
\text { characterized mainly by a specific lexicon. Within the many touristic attractiveness, food and } \\
\text { wine are representing a specific marketing sector for the companies, and also for new } \\
\text { professional profiles like the so-called influencers. Through the analysis of websites and } \\
\text { Instagram posts this paper highlights the importance of the customization of messages in talking } \\
\text { about food and wine for touristic purposes. Furthermore, it confirms how the language of } \\
\text { tourism should be considered as a peculiar and highly variable specialized language. }\end{array}$
\end{tabular}

Keywords: language of tourism, language variation, Italian, food and wine tourism

\section{INTRODUCTION}

Over the last few years, food and wine have become determining factors when it comes to choosing holiday destinations. People are interested not only in the monuments, museums and other places of interest a certain area has to offer, but they also want to know more about local people's culture and lifestyle by eating what they eat and drinking what they drink. In the digital age, travellers are able to collect all the information they need before departure by simply clicking on a link on their smartphone, and the quality of said information is likely to influence their final decision. For this reason, both tour operators and companies that work in the industry have developed new ways to inform and attract potential clients, mainly by using the internet. This social revolution in touristic management reflects on the way language is used on the web for specific purposes: the so-called language of tourism is influenced by the communicative needs and the different social networks.

The Italian language of tourism has been the subject of many different investigations, from the perspective of both language variation (e.g., Calvi, 2000) and language teaching (e.g., Balboni, 2000; Zanasi, 2012, just to mention a few studies on this topic). In this paper, the aim is to focus on the specific topic of online wine and food guides, and on websites and Instagram blogs on the same topic in order to identify which communicative strategies are preferred in the different online environments. In particular, we will try to answer the following research questions:

1) Which are the linguistic peculiarities on the different websites?

2) Is it still possible to consider the language of food on social media as a language of tourism?

The paper is structured as follows: we will first present the theoretical concepts that have guided the overall data collection and analysis; we will then introduce the data, the different social media considered here, and explains how data were collected and prepared for the analysis. The analysis has been divided between the morphosyntactic and the lexical level, with some final considerations on the customization of the message. We will discuss these results in light of what we know about special languages, and, in particular,

Copyright (c) 2021 by authors; licensee OJCMT. This article is an open access article distributed under the terms and conditions of the Creative Commons Attribution License (http://creativecommons.org/licenses/by/4.0/). 
the language of tourism. Finally, we will present some conclusions of the research and the further perspectives of the work.

\section{THE LANGUAGE OF TOURISM: VARIATION WITHIN SPECIALIZED LANGUAGES}

Sociolinguistic research has repeatedly emphasized how variation is one of the main characteristics of language (see Labov (1972) for a comprehensive introduction on the topic). In this perspective, languages can be considered as dynamic entities which take different forms and adapt to the culture and history of the speech communities in which they are in use. Nowadays, Coseriu's (1980) distinction between different dimensions of variation (i.e., diatopic or areal, diastratic, diaphasic or stylistic, and diamesic) has been widely accepted. In particular, when considering the linguistic use on blogs and social media with respect to the language of food tourism, all these dimensions are intertwined: peculiar dialectal terms could appear according to the area the product is from, or to enhance the affiliation of the producers to a certain place.

With respect to the stylistic dimension, the language of tourism could be included among the so-called specialised language, as defined by Sobrero (1993): according to this usual classification, specialised languages present lexical and morpho-syntactic peculiarities which distinguish them from ordinary language. Furthermore, common terms of the language assume specific values and meaning in a specialized language. The languages of technology and of economy are considered common examples of specialised languages, but Calvi (2011) has commented on how the language of tourism should also be considered one of these.

However, many scholars have emphasized how it would be better to consider the language of tourism as a comprehensive term for including different sub-sectors. Indeed, Calvi $(2000,2011)$ and then Mauri (2014) have emphasized how there are different genres of the language of tourism, and how these genres vary according to the communicative modalities (even before the developing of the web 2.0) and the recipient of the communication. Recently, Hausendorf and Müller (2016) have analysed the role of verbal and non-verbal language in shaping the different kinds of touristic communication or communication towards tourists. Many studies have focused on audio-guide (e.g., Fandrych \& Thurmair, 2016), tourist guide, travellers' blogs or tour visits in the museums (e.g., Brito, 2012) also from the point of view of pragmatics and discourse analysis. As pointed out by Ravetto (2018), the rapid development of the web poses new challenges for the analysis of the language of tourism.

Calvi (2011, p. 154) notes how, nowadays, travellers can rely on a much greater variety of resources, namely pamphlets, catalogues and websites, which have deeply changed the way people live the tourist experience. Social networks, blogs, chats and podcasts are fundamental in giving tourists all the necessary information and recommendations they need before their trip. Therefore, companies in the sector are evolving and developing online portals which are accessible from every corner of the world and at any moment. This resolves in new ways of promoting tourism: the keyword is "experience", everything revolves around the desire to provide unique and exciting experiences, creating personalised messages for each type of customer and involving them in the promotional activity (see also Agyeiwaah et al. (2019) for a recent overview about the phenomenon of food and wine tourists). Along with the evolution of the means and modes of information, a change in trend regarding the factors that influence the behaviour of modern travellers: according to the UNWTO, the United Nations World Tourism Organization ${ }^{1}$ local food and wine are becoming more and more relevant in the choice of one's holiday destination, increasing media's attention and making food and wine tourism one of the most dynamic segments of the market.

This change in the way the touristic communication is thought and addressed implies a change in the linguistic strategies adopted, both because of the limitations and possibilities of the new social media, and because of the desire to provide a closer focus on the costumer (e.g., Wang, Tang, and Kim (2019) on customers' online reviews of restaurants). In the digital era, people are accessible at any given moment, they can be reached fast and easily and they can be individually examined in their taste and wishes. Thus, it comes as no surprise that modern tourists are often seen as pretentious and generally having high expectations: they ensure that their needs and preferences are clear, and they want them to be fulfilled. Any entrepreneur who wants to seize the new market opportunities has to keep in mind how important it is to develop

\footnotetext{
${ }^{1}$ https://www.unwto.org
} 
innovative marketing strategies which adapt to the new means of communication. The quantity and quality of informational content has to be appropriate in order to make planning the trip fun and pleasant. Moreover, if expectations are met, travellers are more likely to share their positive experience online through blog posts, vlogs and stories, that will in turn inspire other people. User-generated content (UGC) plays a major part in affecting people's decisional processes, as it is considered more reliable than official information (see Timoshenko \& Hauser, 2019). The key role of an effective marketing initiative has been demonstrated by several recent studies: for example, a research carried out by Synovate and commissioned by Google reveals that $41 \%$ of the users who wished to visit Italy eventually settled for other destinations because they could not find adequate information on the internet (Granieri \& Perri, 2010, p. 46). Modern tourists do not like to improvise, they love to have everything they need at their fingertips and they demand attentive, high quality service.

\section{Food and Wine Tourism: Communicative Challenges}

The growing interest of the linguistic research on the language of tourism should also consider how the web shapes the communication towards tourists in different ways. For this reason, in this research we try to compare different text types that deal with food and wine tourism. In English many phrasebooks exist (e.g., Morris, 2002) or analysis of International Business English (Dubicka \& O'Keefe, 2003; Harding \& Duckworth, 1998). Indeed, studies focused on the analysis of written texts in relation to the language of tourism are still quite scarce, at least for what concerns the Italian language.

The decision to narrow the research down to this specific sector of touristic communication is determined by the increasing importance, as mentioned above, of food and wine in selecting one's travel destination (Croce \& Perri, 2017). People are deeply fascinated by local people's lifestyle and culture and wish to eat what they eat and drink what they drink. Sharing stories and experiences over a nice glass of wine accompanied by some local specialties has become a shared dream among modern tourists. Italy in particular is synonym with quality of life regarding natural beauties, historical heritage, but most of all regarding food and cookery.

According to the Food Travel Monitor 2016², the so-called "Bel Paese" appears among the most popular enogastronomic destinations in the world, together with other attractive locations like France, Spain and Australia. As it emerges from high-ranked food-guides (e.g., Gambero rosso), the profile of the typical enogastronomic tourists, both Italian and foreigners, is that of a couple interested in visiting farms and wineries and tasting local products; some Italian regions appear to be preferred, such as Tuscany, Piedmont, Sicily and Emilia-Romagna. As for the age of the food-travellers, all generations are involved, especially the socalled X-Generation (i.e., the ones born between 1965 and 1980, and currently between 41 - 55 years old) but also the Y- Generation and the Millennials (i.e., the ones born between 1981 and 1996 and are currently between 24 - 40 years old).

Among the varieties of possible texts produced on the topic of food and wine tourism, we decided to furtherly focus our research on written texts with a promotional purpose. These texts show a combination between elements which are peculiar to the specialized languages and features proper of the common language. This happens because their purpose is usually to convey technical information to non-specialists (popularization, cf. Guido 2017). In these texts, which aim to provide useful and practical information, we would expect the referential function (the most denotative one, related to the content of the message) to be dominant, but this is not always true. The emotive function plays a significant role: words are not only used to describe and inform, but they are designed to call forth positive emotions, to involve and persuade the reader (see Lestari (2019) for a recent and comprehensive review).

Concerning food and wine tourism, it is possible to distinguish between three main textual resources: traditional travel guides, content generated by the tourist companies and user generated content. Traditional travel guides are quantitatively numerous, often published annually, and organized for guiding the reader to discover top quality products and riveting locations. Nowadays, famous travel guides such as the Michelin Guide, but also Gambero Rosso and II Golosario (both very popular in Italy) provide complete and interactive

\footnotetext{
2 The World Food Travel Monitor is the most comprehensive international study on enogastronomic tourism, carried out by the World Food Travel Association. The aim is to provide information about the behaviour, attitudes, preferences and spending of food travellers around the world so that businesses can more strategically target the market.
} 
websites, managing to entertain and arouse people's curiosity. We choose these three travel guides, and in particular the latter two, because they are very popular in Italy also during the spread of the COVID-19 Pandemic ${ }^{3}$.

Contents generated by the companies are represented by both paper and digital advertising produced in order to promote the activities and excellences. It comes without saying that in the digital era, every company wanting to be competitive in the tourism sector has to be able to use websites and social networks wisely: tourists are not only attracted by the product itself, but also by the way it is presented and promoted. For this reason, many entrepreneurs rely on advertising agencies to develop the most effective strategies for enhancing the unicity of their work; this also implies the creation of new working figures like the social media manager, and the need for these new workers to have specific knowledge on how different languages could be used for specialized purposes (e.g., Fujita 2019). Finally, user generated content assumes a key role in enogastronomic tourism promotion, especially through the emerging figures of the so-called "influencers". Generally speaking, these people are passionate and engaged in one peculiar activity (in our case, food and wine), and regularly post content on their social media in order to share their experience. However, these contents are explicitly created to influence the decisions of the audience as well (that is, the followers).

\section{DATA COLLECTION}

For the purposes of this study, we will consider texts taken from the three aforementioned categories, in order to identify the most powerful linguistic strategies used in tourist promotion. In particular, we will focus on three different levels of analysis: lexicon, morphosyntax and on the customization of the text according to the user. The corpus used in this research contains samples taken exclusively from online sources, since they are easily accessible to everyone and they get regularly updated.

In particular, we analysed two articles published by one of the best-known enogastronomic travel guides in Italy, Gambero Rosso (La Forza del Territorio e II Pranzo del Purgatorio), and two articles taken from other popular websites (Siciland.com and touringclub.it), of approximately 1000 words each. Moreover, we considered the reviews of the top Italian restaurants around the world published by Gambero Rosso (28 reviews, of approximately 150 words each).

With regard to the content created by the companies in the industry, we focused on the websites of two wineries located in Piedmont, Northern Italy: Cascina Chicco (cascinachicco.com) and Cantine Povero (cantinepovero.com). The selection of these two companies has been made because they share the same geographical area, therefore there will not be difference relatable to geographic variation in the use of language. For both companies, we considered the websites and in particular the part of the company's selfpresentation to the audience and its history.

Finally, some texts were taken from the Instagram profiles of three notorious Wine influencers, Chiara Giannotti (Instagram/vino.tv), Cor Vino (Instagram/cor_vino) and The Wine Girl (Instagram/the.wine.girl). The selection of these influencers has been on the ranking proposed by Kim (2018) of the top 9th Italian wine influencers. In this case only the posts made by the influencers from January to February 2020 have been considered, by excluding the comments or reactions provided by the followers, and also by considering only those posts (the majority) related to wine or food. These posts were transcribed in a text editor, by maintaining possible misspellings and hashtags, and by providing the web reference for each post.

\section{ANALYSIS}

\section{Lexical Level}

As we have seen, lexicon plays a central role in defining the language of tourism as a specialized language, but also in shaping different texts for promotional purposes. In particular, in the food and wine sector the

\footnotetext{
${ }^{3}$ Both the Gambero Rosso and the Golosario have online regular updates concerning food and wine tourism as well as the possibility of food delivery. This has been crucial during the COVID-19 pandemic in March, as many high valuated restaurants adapted to changing circumstances and the restrictions (cf. https://www.linkiesta.it/2020/05/come-cambierala-critica-gastronomica-losservatorio-privilegiato-della-rossa/).
} 
lexicon found in our corpus could be included into specific semantic fields: cookery, agriculture, food history, art and folklore, technologies. Cookery refers to the abundance of use of receipts, description of specialities and peculiar techniques adopted in a specific restaurant or place, while references to agriculture are used to enhance the feeling of territoriality, and also to provide additional information about the origin and processing of typical products, in which modern tourists appear to be increasingly interested (seasoning, maceration, decantation, aging on yeast fermentation).

In the communication produced by the tourist companies analysed, many references were made to the history of the company itself, as in the example quoted in (1) from the Cascina Chicco website. In this and the following examples the plain text is provided in the original language, which could be Italian, English or both, since, as we will see the use of both languages or of English as a lingua franca is quite common.

\section{Example (1)}

It. Ci hanno sempre chiamati i Chicu, ovvero i Chicco. Dal nonno Ernesto ai miei figli, questo non solo è lo stranome che identifica la storia della nostra azienda, ma è molto di più: in sé porta l'affetto, la stima, l'amicizia e l'appartenenza alla comunità della nostra stessa famiglia.

Engl. The Chiccos have always been called "Chicu". From Nonno Ernesto to my children, this nickname has symbolized the history of our winery. But it signifies much more. It represents the affection, esteem, friendship and community that our family is a part of.

In the text quoted in (1) it is possible to note how the name of the company is used to trace back the history of the company, and also to explicitly refer to the social values to be shared with the costumer: the use of a family history helps in creating an emotional connection with the customer.

The language of tourist promotion also shares many features with the language of advertising, since it involves two interacting processes, communication and persuasion, that are typically to be found in advertisements. The aim is not only to provide useful information, but also to fascinate and persuade the potential clients to visit the areas that are described. Therefore, together with practical suggestions, we may find an "extreme language", with a vocabulary carefully chosen to promote positive associations in the mind of the reader.

Great evidence of this can be found in restaurant and hotel reviews provided on the websites. For example, we considered one of the main food and wine travel guides in Italy, Gambero Rosso, to illustrate how evocative and exaggerated this type of language can be. Evaluative adjectives, superlatives, hyperboles and metaphors are widely used to make descriptions more vivid and captivating (popular, elegant, not to be missed, awardwinning, mind-blowing, mouth-watering). The examples in (2) provides evidences of this statement.

\section{Example (2)}

(a) The cuisine is very much traditional and it always boasts valuable technical level, be it the gnocchi with black truffle or morels, or a perfectly cooked roast rabbit leg, with polenta, ham and radicchio correctly contrasting sauces. Perfect cooking times make the difference here, it's a matter of texture, it's a matter of taste.

(b) A great example of virtuous restaurant service. [...] is the exquisitely Mediterranean cuisine marked by crisp lightness. The service is exceptional, starting from the wine [...] one of the most beautiful and articulated wine collections in Europe, boasting character and research.

On the other hand, we have to remember that an excessive use of superlatives could have the opposite effect: modern consumers look for directness and honesty, and are less tolerant for hard-selling campaigns: the more they perceive an effort in emphasizing the quality of the products, the more suspicious and annoyed they get.

Rarely do we find adjectives implying negative connotations and when they are used they are usually followed by other positive adjectives and expressions which allow us to counterbalance, drawing the attention on the most positive features of the reality that is described (limited but top-quality wine selection). An example in this sense is provided in (3), taken from another review made on the Gambero Rosso website. It 
is possible to notice how the negative opening statement is immediately balanced by the adversative rather which open the second sentence and the general positive review.

\section{Example (3)}

It will not be the beautiful but not very characterised environment [...] that makes you feel like you're in Sicily. Rather, it's the dishes that the faithful hand of [...] takes directly from the Duomo di Ragusa by Ciccio Sultano.

Another interesting feature of the language of tourism is the familiar lexicon. Since the purpose of travel guides is to capture and maintain the attention of the reader, vocabulary tends to be drawn from colloquial language. Moreover, we can often find fixed and idiomatic expressions typical of informal registers (dish that made us prick up our ears, a pizza to die for).

Finally, it is not uncommon to encounter foreign terms and borrowings. In the last thirty years, globalization and new technologies have led to an exponential growth in the contacts and exchanges between nations, and thus to the birth of international companies that need to communicate with customers speaking different languages. In particular, the use of English as a lingua franca has become an essential marketing tool and entrepreneurs often turn to professionals for the creation of multilingual websites. Texts promoting food and wine tourism are rich in foreign words defining typical products and dishes, as we can see (4).

\section{Example (4)}

(a) Among the classics in the excessively ample menu is the risotto, we tasted the pizzaiola version, with the bold acidity of the tomato is balanced by the Alaskan black cod with fermented soy: a dish is sharp and intense. Sweet endings shine thanks to the four-star light and fragrant Chiacchiere Napoletane.

(b) [...] succeeds in spite of the lack of more international proposals. One of these certainty is the spaghetti with sardines, lamb ravioli and the "chiaromontana piglet". In our visit we also had a fabolous palermo-style red mullet and some super thin and tasty tortelli filled with ricotta, tuma cheese, served with a lamb ragout and cime di rapa. And the cannoli, of course!

Similarly, posts on social networks are usually written both in English and another language, or sometimes just in English. This is particularly evident for Instagram posts in which the audience is intended to be international, and thus English is used as a vehicular language. The example quoted in (5) presents a case of an Instagram post in which the influencer Chiara Giannotti with his blog @vino.tv introduces the wine Brunello di Montalcino. The original post, whose link appears in the note, presents a picture of the user's hand holding the new bottle of wine in the foreground, and two girls in the background who possibly represent the two vintages commented in the text.

\section{Example (5). Instagram post by @vino.tv ${ }^{4}$}

\#benvenutobrunello!!! Si presentano sul mercato due ottime annate, la 2015 per il \#brunellodimontalcino, premiata con le 5 stelle e la 2018 per il \#rossodimontalcino... ... purtroppo non sono riuscita ad assaggiarli tutti, ma tra quelli fatti vi mostro qualche assaggio che mi è rimasto nel cuore ... guardate nelle stories per $\mathrm{i}$ singoli commenti ! A voi quali sono piaciuti di più?

Gв Welcome Brunello!!! Two excellent vintages are on the market, 2015 for the \#brunellodimontalcino, awarded with 5 stars and 2018 for the \#rossodimontalcino unfortunately I have not been able to taste them all, but among those made I show you some samples that I appreciated very much ... look in the stories for single comments and more! Which one is your favorite \#brunello?

The text in (5) is in Italian and English, with the latter being an explicit translation of the Italian message and marked with the acronym "GB". This could also indicate a specific target customers for this blog, that is people from Great Britain and not international people in general. The use of hashtags appear to be restricted

\footnotetext{
${ }^{4}$ https://www.instagram.com/p/B86_yhfi50d/
} 
to the name of the wine. It is also important to notice the use of direct questions to address the audience and invite it to comment the post.

\section{Morphosyntactic Level}

Morphosyntactic phenomena are usually considered to be less representative than lexicon in the analysis of technical languages. However, by focusing mainly on the company websites, we can observe several recurring features. Broadly speaking, the distinctions between speech and writing appear to be blurred, as it has generally been observed for CMC (Communication Mediated by Computer, Thurlow et al. (2004) inter alia, Fiormonte (2003), Pistolesi (2004), Lorenzetti and Schirru (2006) specifically on Italian). The syntax is generally simple, based on short sentences and coordination. Yet subordination and longer sentences are widely used in the description of accommodations, restaurants, locations etc. in order to confer elegance and slow the pace of the discourse, as we can see in (6) and (7).

\section{Example (6): Cascina Chicco website}

The new cellar of Cascina Chicco fosters a unique and welcoming environment, where technology and tradition live in conviviality in a spectacular underground facility that displays original bricks and outcrops of chalk crystals. A tribute to the extraordinary land of Roero and its wines.

\section{Example (7): Cascine Povero website}

A perfect symbiosis, a strong union between man and Nature where each stage is supported by an experienced oenological practice that allows the glass to become a veritable poetry of the senses: balance, immediacy, depth, preciousness.

Moreover, it is not unusual to encounter rhetorical devices such as enumerations of local specialties, processing methods and places of interest, which are listed one after the other (by using both asyndetons and polysyndetons) to create an evocative effect. Lists of adjectives usually include three elements in order to highlight positive qualities on different semantic areas: in the example in (8) the adjectives "new, efficient, and beautiful" as referred to the cellar of storage are meant to emphasize the technological and the aesthetic aspect of the place.

\section{Example (8): Cascina Chicco website}

A new, efficient, and beautiful cellar where every bottle is properly placed and refined. Over 5000 square metres that descend 28 metres deep under the hill, divided into separate areas for ageing, barriques, tasting room, storehouse, and crutins (small cellars) dug by hand in the naked rock.

While companies seem to prefer for their websites a communication style which is both clear and sophisticated, social networks adopt a more familiar approach, in the attempt of resembling everyday conversation. For example, we may find many rhetorical questions, direct address to the audience, and also exclamations in order to emphasize the emotive register and help realize the phatic and conative functions. These are all meant to directly involve the addressees of the communication, namely the followers. In (9) there are two examples of this kind of communication: while the first one ( 9 a) belong to an influencer on Instagram, the second $(9 \mathrm{~b})$ is extracted from the online website of the Gambero Rosso magazine.

\section{Example (9): Wine on Instagram (a) and on the specialized website Gambero Rosso (b)}

(a) Can you bottle alpine landscape and Mediterranean sun? Apparently, you can!

(b) Does Copenhagen have more bicycles than restaurants? Hard to say, but what's for sure is that something in this city is stimulating taste buds and minds. Copenhagen is a place of research, featuring a sensibility that pushes Italian restaurants in Denmark to keep high standards and never rest on their laurels.

The main difference between the two examples quoted in (8) is the brevity of the Instagram post if compared to the website news. In the second example, indeed, there is an opening question followed by an 
explanation with different details, whereas in the first case the explanation of the opening question could be found in the images related to the post.

In terms of verb tenses, the present tense is prevalent since it is particularly suitable for writing descriptions and practical information, while the past tense tends to be avoided. If used, it is usually to refer to the traditions and history of the place and the company.

\section{DISCUSSION}

\section{The Language of Tourism as a Specialized Language}

The analysis conducted on the lexicon and the morphosyntax used in different websites pertaining to food and wine tourist promotion has shown how the language of tourism could resemble a specialized language, but that should be considered as highly variable according to the diamesic dimension. This variability should be further stressed from the point of view of language teaching, and in particular for the teaching of English language for specific purposes. Furthermore, the language of food and wine for tourist promotion has to deal with peculiar communicative requirements like the identification and involvement of a specific target among the audience (see also infra).

Market research and data show that Millennials are slowly becoming more interested in food and wine tourism, meaning that companies have to find new ways to attract and communicate with their potential clients. Social networks, such as Instagram and Facebook, play such an important role in the involvement of the youngsters, combining the concepts of tradition and accessibility. It is not rare for a company to recruit or even create influencers and opinion leaders, so that they can work as brand ambassadors for their products and organization. This new trend relies on the assumption that the best advertising is never coming from the producer himself: followers on social networks deeply trust these strong personalities, considering them as gurus and reliable advisors, so producers turn to these figures to make their company known among the younger generations.

Wine and food influencers are often enthusiasts who decided to turn their passion into their full time job. They are not improvisers, but incredibly passionate people who share their experiences and competences with great professionalism and dedication. Therefore, the language they use is not devoid of technicalities, while still being spontaneous, direct and clear in order to create a strong emotional connection with the reader. As in travel guides, also on social networks we can come across a large amount of idiomatic, informal expressions, and countless foreign lexemes.

Finally, what we can say is that there is little evidence of the typical features of specialized languages (nominalization, passive structures, etc.) emerging from the analysed texts, with the exception of verb phrase ellipses (cf. example 10 from the website of Cantine Povero), which seem to occur quite frequently. This is also online with previous studies on the language of tourism, that have already emphasized how it has to be considered as a special and multi-levelled specialized language.

\section{Example 10: Cantinepovero and ellipses}

A perfect symbiosis, a strong union between man and Nature where each stage is supported by an experienced oenological practice that allows the glass to become a veritable poetry of the senses.

\section{The Customization of the Message}

Early in this paper we have discussed the key role that the customer plays in the era of modern marketing: every company wanting to be successful has to concentrate on offering the most unforgettable experience to its clients. This implies that the first necessary step in the development of an effective communication strategy is getting to know the audience. Companies are aware of the unlikelihood of their products to meet the needs of the entire market: potential clients are too many, they are too diverse in their behaviour, wishes and expectations and they are often too geographically distant. These different aspects have to be carefully analysed in order to group consumers into different categories on the basis of demographic, social, economic and psychological variables. After that, the designated marketing managers will have to select the most promising segments for their products to be addressed to, considering the attractiveness and potential of 
each category, the compatibility with the company resources and values, and also taking account of the competitors. It is to be expected that consumers who belong to the same segment, will respond in a similar way to the same marketing initiatives; if a promotional campaign is intended for teenagers or young adults, for example, it will more likely appear on social networks than on a newspaper. The target audience has thus great influence on the elaboration of promotional messages, affecting the mode, timing and setting of the communication.

Secondly, the company has to set its own main goal, that is to say the response they want to obtain from the target customers: it could be purchasing a product, visiting a place of interest or staying at a particular hotel. Moreover, they definitely want to be aware of their competitors and develop strategies to gain a competitive advantage over other companies in the field: travellers who think about a holiday dedicated to the discovery of local specialties and beauties will choose the best destination according to their own perception of a wide range of factors, such as prices, convenience and obviously the possibility to access exhaustive information about it. Being successful in the market does not always mean being the one offering the best quality products at the lowest prices, but it certainly means that a company is able to effectively communicate its values, vision and mission to the right clients, and can do it better than its competitors.

During the actual phase of elaboration of an effective promotional message, marketing managers have to figure out a way to capture the attention, arouse the interest and obtain the response they are looking for. This result may be achieved in different ways, for example by empathizing with the reader, sharing the same values and sense of morality. With regard to the means of communication, the operator has to make several decisions about the communication style, register and format. In the case of online advertising, the focus will be on titles, fonts, images and colours, while when it comes to radio advertising it is necessary to choose the right words, sounds and music. The style of the message also depends on the greater or lesser impersonality of the communication channel (Kotler \& Armstrong, 2015).

- Personal communication channels: two or more people communicate directly with each other via email, social network, on the phone, etc. They allow a feedback and make it possible to customize the message. Direct marketing is a type of communication which uses personal channels, because the company contacts the costumer without any intermediary to communicate information about its products and activities.

- Mass communication channels: major media that carry a message without allowing contact or feedback, such as television and newspapers.

Finally, managers should regularly verify that the existing communication strategies match the demands of the target customers. In fact, especially regarding food and wine, the consumer taste is changing faster than ever.

\section{CONCLUSIONS AND FURTHER PERSPECTIVES}

The language of tourism proves to be extremely variable due to the different websites: although similar communicative strategies are adopted, the difference between the use of the main features of this specialised language lies in the different target the communication is intended for. In particular, with respect to other specialized languages, when talking of wine and food for touristic purposes, the emotional component is of extreme importance: tourists should be able to a have a foretaste of the typical flavours and aromas of a certain area just by reading an article or a post on their smartphone.

Even though that the language of tourism does not seem to follow all those strict rules that affect the specialized languages, it still shows several interesting features at a lexical, syntactic and textual level. The lexicon, which is mostly taken from the semantic fields of other specialized languages, is carefully chosen in order to involve the reader and present reality in a picturesque and fascinating way. In most of the analysed texts we found a large amount of evocative adjectives, superlatives, hyperboles and metaphors which help make descriptions more vivid and contribute to generate positive feelings. Syntactic solutions are aimed at creating a direct connection with the reader as well, but particular focus has to be placed on the paratextual element as a determining factor in capturing and maintaining the attention. In fact, what emerges from our research is that modern tourists prefer a clear, simple and accurate language accompanied by a minimal and intuitive interface. 
Further studies on the language of tourism, and, in particular, on the enogastronomic domain, may investigate how different languages are used to convey different images of both the producers (either the restaurant or the food company) and the target audience. Moreover, a specific quantitative linguistic analysis of hashtags and their multilingual use could be of interest as well as the analysis of neologisms and metaphors associated with food and wine in touristic communication on the internet.

Author contributions: All authors were involved in concept, design, collection of data, interpretation, writing and critically revising the article. All authors approve final version of the article. For the requirements of the Italian Academy, Silvia Balsamo is responsible for the paragraph "Food and wine tourism", other than for data collection and analysis of the present work; Chiara Meluzzi holds responsibility for the introduction, theoretical framework, discussion and conclusion.

Funding: The authors received no financial support for the research and/or authorship of this article.

Declaration of interest: Authors declare no competing interest.

Data availability: Data generated or analysed during this study are available from the authors on request.

\section{REFERENCES}

Agyeiwaah, E., Otoo, F. E., Suntikul, W., \& Huang, W.-J. (2019). Understanding culinary tourist motivation, experience, satisfaction, and loyalty using a structural approach. Journal of Travel \& Tourism Marketing, 36(3), 295-313. https://doi.org/10.1080/10548408.2018.1541775

Balboni, P. (2000). Le microlingue scientifico-professionali: natura e insegnamento [Scientific-professional microlanguages: nature and teaching]. UTET.

Brito, L. M. (2012). Intercultural interpretation strategies in the museum: the case study of a guided visit to the Coach Museum in Lisbon. Revisit Turismo y Desenvolvimento, (17/18), 437-450. https://comum.rcaap.pt/bitstream/10400.26/2353/1/2012.01.001_.pdf

Calvi, M. V. (2000). Il linguaggio spagnolo del turismo [The Spanish language of tourism]. Baroni.

Calvi, M. V. (2011). La lingua della comunicazione turistica [The language of tourism communication]. Rivista di Scienze del Turismo, 2(3), 153-158. https://www.ledonline.it/index.php/Rivista-ScienzeTurismo/article/view/384

Coseriu, E. (1980). "Historische Sprache" und "Dialekt" ["Historical Language” and "Dialect”]. In J. Göschlel, I. Pavle, \& K. Kehr (Eds.), Dialekt und Dialektologie [Dialect and dialectology] (pp. 106-122). Steiner.

Croce, E., \& Perri, G. (2017). Food and wine tourism. Cabi. https://www.cabi.org/bookshop/book/9781786391278/

Dann, G. (1996). The language of tourism. A sociolinguistic perspective. Cab International.

Dubicka, I., \& O’Keeffe, M. (2003). English for international tourism: pre-intermediate students' book. Longman.

Fandrych, C., \& Thurmair, M. (2016). Audioguides: die Inszenierung von Kunst im Hörtext [Audio guides: the staging of art in the audio text]. In H. Hausendorf \& M. Müller (Eds.), Handbuch Sprache in der Kunstkommunikation [Handbook Language in Art Communication] (pp. 380-400). de Gruyter. https://www.degruyter.com/view/book/9783110296273/10.1515/9783110296273-018.xml

Fiormonte, D. (2003). Scrittura e filologia nell'era digitale [Writing and philology in the digital age]. Bollati Boringhieri.

Fujita, R. (2019). English for tourism and hospitality. In H. Terauchi, J. Noguchi, \& A. Tajno (Eds.), Towards a New Paradigm for English Language Teaching (pp. 172-180). Routledge. https://doi.org/10.4324/9780429423963-16

Granieri, G., \& Perri, D. (2010). Linguaggi digitali per il turismo [Digital languages for tourism]. Apogeo.

Guido, Maria Grazia. 2017. Strategie mediate da ELF per la promozione della dieta mediterranea come prodotto di lusso tra turisti e migranti. Lingue e Linguaggi 20: 69-86. http://sibaese.unisalento.it/index.php/linguelinguaggi/article/view/17349/14841

Harding, K., \& Duckworth, M. (1998). Going international: English for tourism. Oxford University Press.

Hausendorf, H., \& Müller, M. (2016). Handbuch Sprache in der Kunstkommunikation [Handbook Language in Art Communication]. de Gruyter. https://doi.org/10.1515/9783110296273

Kim, S. (2018). \#nofilter: 12 q\&a with 9 italian wine influencer. Verona: Positive Press.

Kotler, P., \& Armstrong, G. (2015). Principi di marketing [Marketing principles]. Pearson.

Labov, W. (1972). Sociolinguistic Patterns. Philadelphia University Press. 
Lestari, D. (2019). Persuasive Function in Food and Beverage Service: A Sociolinguistics Approach. Advances in Social Science, Education and Humanities Research, 353, 22-28. https://doi.org/10.2991/icosihess19.2019 .4

Lorenzetti, L., \& Schirru, G. (2006). La lingua italiana nei nuovi mezzi di comunicazione: SMS, posta elettronica e Internet [The Italian language in the new means of communication: SMS, e-mail and the Internet]. In S. Gensini (Ed.), Fare comunicazione [Make communication] (pp. 71-89). Carocci.

Mauri, E. (2014). L'italiano delle guide turistiche: uno studio della lingua orale del turismo [The Italian of tourist guides: a study of the oral language of tourism]. Italiano LinguaDue, 1, 232-248. https://riviste.unimi.it/index.php/promoitals/article/view/4234

Morris, C. E. (2012). Flash on English for tourism. ELI.

Pistolesi, E. (2004). II parlar spedito. L'italiano di chat, e-mail e SMS [Speaking quickly. The Italian of chat, e-mail and SMS]. Esedra.

Ravetto, M. (2018). Generi della comunicazione turistica tra educazione e intrattenimento [Genres of tourism communication between education and entertainment]. Sociolinguistica, 32(1), 225-236. https://doi.org/10.1515/soci-2018-0019

Sobrero, A. (1993). Introduzione allitaliano contemporaneo [Introduction to contemporary Italian]. Editori Laterza.

Thurlow, C., Lengel, L., \& Tomic, A. (2004). Computer mediated communication. Sage.

Timoshenko, A., \& Hauser, J. R. (2019). Identifying customer needs from user-generated content. Marketing Science, 38(1), 1-20. https://doi.org/10.1287/mksc.2018.1123

Wang, X., Tang, L. R., \& Kim, E. (2019). More than words: Do emotional content and linguistic style matching matter on restaurant review helpfulness?. International Journal of Hospitality Management, 77, 438-447. https://doi.org/10.1016/j.ijhm.2018.08.007

Zanasi, L. (2012). Lingua speciale e performances in L2 [Special language and L2 performances]. Studi Italiani di Linguistica Teorica e Applicata, XLI(1), 49-66.

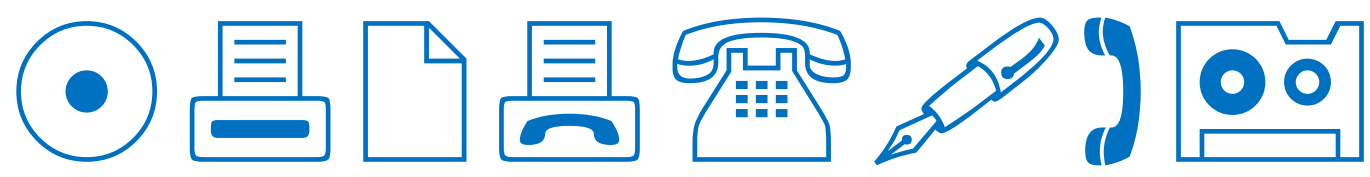

